\title{
Adiponectin and Cardiovascular Outcomes among Hemodialysis Patients
}

\author{
Emad Abdallah $^{\mathrm{a}}$ Emam Waked $^{\mathrm{a}}$ Malak Nabil $^{\mathrm{a}}$ Omnia El-Bendary ${ }^{\mathrm{b}}$ \\ a Department of Nephrology and bepartment of Clinical Chemistry, Theodor Bilharz Research Institute, \\ Cairo, Egypt
}

\section{Key Words}

Adiponectin - Cardiovascular disease - End-stage renal disease $\cdot$ Hemodialysis

\begin{abstract}
Background: Adiponectin (ADPN) levels are consistently elevated among patients with advanced chronic kidney disease, but its relationship with cardiovascular outcomes in this population remains controversial. The aim of our study was to measure the plasma levels of ADPN in patients with end-stage renal disease on maintenance hemodialysis (HD) and we studied its correlates to cardiovascular outcomes and mortality. Methods: Our study included $133 \mathrm{HD}$ patients (79 male and 54 female patients) with a mean age of $54.6 \pm$ 17.3 years who had been receiving regular HD for at least 6 months in the nephrology units of Theodor Bilharz Research Institute, Cairo, Egypt. The clinical and biochemical correlates of plasma ADPN levels were investigated and the predictive power of ADPN levels with respect to cardiovascular events and mortality was prospectively tested in HD patients, who were monitored for $24 \pm 9$ months. Plasma ADPN levels were measured by using a sensitive enzymelinked immunosorbent assay. Results: Plasma ADPN levels were 3 times higher $(p<0.0001)$ among HD patients $(18.1 \pm$ $6.8 \mu \mathrm{g} / \mathrm{ml})$ than among healthy subjects $(6.2 \pm 1.8 \mu \mathrm{g} / \mathrm{ml})$. Plasma ADPN levels were lower $(p<0.007)$ among patients who experienced new cardiovascular events (13.9 $\pm 6.4 \mu \mathrm{g} /$ $\mathrm{ml})$ than among event-free patients $(18.6 \pm 8.4 \mu \mathrm{g} / \mathrm{ml})$. The relative risk of cardiovascular events was 1.96 times $(95 \%$
\end{abstract}

confidence interval 1.290-2.977, $\mathrm{p}=0.0016$ ) higher among patients in group 1 (ADPN $<15.1 \mu \mathrm{g} / \mathrm{ml}$ ), compared with those in group 2 (ADPN $\geq 15.1 \mu \mathrm{g} / \mathrm{ml}$ ). Plasma ADPN levels were inversely related to $B M I$, insulin levels, homeostatic model assessment index values, triglyceride and LDL-C, CRP and left ventricular mass index. Furthermore, plasma ADPN levels were directly related to HDL-C. Conclusion: Plasma ADPN is an independent (inverse) predictor of cardiovascular events and mortality among HD patients. The directions of the relationships between ADPN and several metabolic risk factors indicate that ADPN has a protective role in prevention of CVD.

Copyright $\odot 2012$ S. Karger AG, Basel

\section{Introduction}

Adiponectin (ADPN), an anti-inflammatory, antiatherogenic and insulin-sensitizing adipokine exists in several isoforms in the circulation. In patients with chronic kidney disease (CKD), circulating levels of total as well as high-molecular-weight ADPN are elevated [1]. ADPN levels have been shown to be lower in males, obesity, insulin resistance, in patients with type 2 diabetes mellitus, coronary artery disease and essential hypertension [2-6]. In contrast, $\mathrm{ADPN}$ is elevated in kidney disease including nephrotic syndrome [7], and particularly in end-stage renal disease (ESRD), with levels up to 3 times higher compared to the normal population [8].

\section{KARGER}

Fax +4161306 1234 E-Mail karger@karger.ch www.karger.com

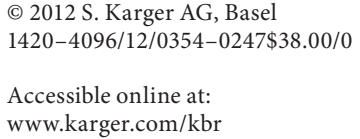

Emad Abdallah, MD

Department of Nephrology, Theodor Bilharz Research Institute

El Nil St., Warrak El-Hader, POB 30

Imbaba, Giza (Egypt)

Tel. +96555006 075, E-Mail emadalimoh@yahoo.com 
Table 1. Demographic, clinical, and biochemical characteristics of the studied groups

\begin{tabular}{|c|c|c|c|c|c|c|}
\hline Variables & $\begin{array}{l}\text { Control } \\
\text { group }\end{array}$ & $\begin{array}{l}\text { All HD } \\
\text { patients }\end{array}$ & $\mathrm{p}^{*}$ & $\begin{array}{l}\text { HD patients with car- } \\
\text { diovascular events }\end{array}$ & $\begin{array}{l}\text { Event-free } \\
\text { patients }\end{array}$ & $\mathrm{p}^{* *}$ \\
\hline Number & 20 & 133 & & 53 & 80 & \\
\hline Age, years & $52.4 \pm 16.3$ & $54.6 \pm 17.3$ & 0.59 & $56.8 \pm 14.6$ & $51.4 \pm 13.1$ & 0.027 \\
\hline Gender, male/female & $11 / 9$ & $79 / 54$ & & $31 / 22$ & $48 / 32$ & \\
\hline Duration of dialysis, months & & $60.4 \pm 18.6$ & & $62.3 \pm 12.5$ & $58.2 \pm 13.4$ & 0.07 \\
\hline BMI & $24.5 \pm 2.3$ & $23.8 \pm 3.6$ & 0.4 & $22.9 \pm 2.6$ & $24.1 \pm 2.9$ & 0.016 \\
\hline Systolic blood pressure, $\mathrm{mm} \mathrm{Hg}$ & $118.2 \pm 19.4$ & $134.6 \pm 24.3$ & 0.004 & $136.6 \pm 23.2$ & $129.21 \pm 18.7$ & 0.04 \\
\hline Diastolic blood pressure, $\mathrm{mm} \mathrm{Hg}$ & $74.3 \pm 18.4$ & $76.2 \pm 19.3$ & 0.68 & $78.7 \pm 16.5$ & $74.2 \pm 13.6$ & 0.08 \\
\hline Smokers & & 34 & & 28 & 6 & \\
\hline Diabetic patients & - & 28 & & 19 & 9 & \\
\hline \multicolumn{7}{|l|}{ Previous cardiovascular events } \\
\hline Angina pectoris & - & 9 & & 8 & 1 & \\
\hline Myocardial infarction & - & 7 & & 5 & 2 & \\
\hline Stroke & - & 4 & & 3 & 1 & \\
\hline Hemoglobin level, g/dl & $13.8 \pm 2.3$ & $11.2 \pm 1.6$ & $<0.001$ & $10.8 \pm 1.3$ & $11.2 \pm 1.4$ & 0.09 \\
\hline S. albumin, $g / d l$ & $4.2 \pm 1.1$ & $3.7 \pm 0.9$ & 0.026 & $36.3 \pm 0.8$ & $3.8 \pm 0.7$ & 0.13 \\
\hline S. calcium, mg/dl & $9.4 \pm 1.3$ & $8.5 \pm 1.2$ & 0.002 & $8.3 \pm 1.3$ & $8.6 \pm 1.4$ & 0.21 \\
\hline S. phosphorus, mg/dl & $4.3 \pm 0.9$ & $5.6 \pm 1.3$ & $<0.001$ & $4.8 \pm 1.6$ & $5.7 \pm 1.4$ & 0.0008 \\
\hline S. total cholesterol, $\mathrm{mg} / \mathrm{dl}$ & $160.4 \pm 37.2$ & $206 \pm 48.2$ & $<0.0001$ & $214.3 \pm 46.7$ & $198.2 \pm 42.3$ & 0.04 \\
\hline $\mathrm{LDL}-\mathrm{C}, \mathrm{mg} / \mathrm{dl}$ & $112.3 \pm 27.2$ & $133.7 \pm 38.2$ & 0.017 & $141.5 \pm 36.4$ & $125.7 \pm 37.2$ & 0.01 \\
\hline HDL-C, mg/dl & $44.8 \pm 13.4$ & $38 \pm 12.1$ & 0.02 & $36.7 \pm 9.4$ & $43.2 \pm 10.3$ & $<0.0003$ \\
\hline Triglycerides, mg/dl & $137.6 \pm 62.3$ & $173.6 \pm 71.3$ & 0.03 & $174.4 \pm 63.2$ & $149.5 \pm 68.9$ & 0.036 \\
\hline S. glucose, $\mathrm{mg} / \mathrm{dl}$ & $84.6 \pm 18.4$ & $120.4 \pm 20.6$ & $<0.0001$ & $123.2 \pm 18.3$ & $117.6 \pm 17.8$ & 0.08 \\
\hline Plasma insulin level, $\mu \mathrm{U} / \mathrm{ml}$ & $13.6 \pm 4.3$ & $18.4 \pm 3.7$ & $<0.0001$ & $20.2 \pm 2.8$ & $16.3 \pm 3.2$ & $<0.0001$ \\
\hline HOMA-R index, $\mathrm{mM} \cdot \mu \mathrm{U} / \mathrm{ml}$ & $3.1 \pm 1.2$ & $4.8 \pm 1.4$ & $<0.0001$ & $5.7 \pm 1.6$ & $3.9 \pm 1.3$ & $<0.0001$ \\
\hline C-reactive protein, $\mathrm{mg} / \mathrm{dl}$ & $1.3 \pm 0.1$ & $8.3 \pm 2.1$ & $<0.0001$ & $9.4 \pm 1.8$ & $7.6 \pm 0.9$ & $<0.0001$ \\
\hline LVMI, $\mathrm{g} / \mathrm{m}^{2}$ & $46.2 \pm 16.3$ & $108.4 \pm 37.5$ & $<0.0001$ & $114.3 \pm 32.6$ & $101.5 \pm 35.2$ & 0.036 \\
\hline Plasma ADPN, $\mu \mathrm{g} / \mathrm{ml}$ & $6.2 \pm 1.8$ & $18.1 \pm 6.8$ & $<0.0001$ & $13.9 \pm 6.4$ & $18.6 \pm 8.4$ & $<0.0007$ \\
\hline
\end{tabular}

${ }^{*}$ p value between all HD patients and control. ${ }^{* *}$ p value between patients with cardiovascular events and event-free patients.

The rise in ADPN with declining glomerular filtration rate (GFR) is hypothesized to be secondary to diminished renal elimination, though the exact role of the kidney in the biodegradation and excretion of ADPN remains unclear. Recent observational studies have shown ADPN to be a novel risk marker of CVD in patients with stage 1-5 CKD. CVD remains a major cause of premature death in patients with CKD [2]. These prospective studies have revealed that low ADPN levels to be predictive of the development of new cardiovascular events in patients with CKD, including the hemodialysis (HD) population [810], while ADPN has been shown to predict the development of type 2 diabetes in renal transplant recipients [11].

\section{Aim of Our Study}

We measured the plasma levels of ADPN in patients with ESRD on maintenance HD and studied its correlates to cardiovascular outcomes and mortality.

\section{Patients and Methods}

\section{Study Design}

Our study included 133 patients with ESRD on maintenance HD (79 male and 54 female patients) with a mean age of $54.6 \pm$ 17.3 years who had been receiving regular HD for at least 6 months, in the nephrology units of Theodor Bilharz Research Institute, Cairo, Egypt. The clinical and biochemical correlates of plasma ADPN levels were investigated and the predictive power of ADPN levels with respect to cardiovascular events and mortality was prospectively tested in our HD patients, who were monitored for $24 \pm 9$ months (range 1-36). Patients with evidence of circulatory congestion (defined as dyspnea, increased jugular pressure, crackles, interstitial edema in chest X-rays, requiring hospitalization or extra ultrafiltration), malignancy and major infections were excluded from the study. This study protocol was approved by the Human Investigation Review Committee and informed consent was obtained from each participant.

The demographic, clinical, and biochemical characteristics of our patients are detailed in table 1 . The control group consisted of 20 healthy subjects matched to dialysis patients with respect to gender and BMI. 


\section{Methods}

Laboratory Investigations

Heparinized blood samples $(15-20 \mathrm{ml})$ were immediately placed on ice, plasma separated within $30 \mathrm{~min}$ of sample collection, aliquoted and stored at $-80^{\circ} \mathrm{C}$. Total cholesterol, LDL-C, HDL-C, TGs, albumin, hemoglobin, calcium, phosphate, and glucose levels were analyzed using standard methods.

ADPN levels were measured using a commercially available enzyme immunoassay kit (R\&D Systems, Minneapolis, Minn., USA). The coefficients of variation for intra- and interassay precision were $<5$ and $<7 \%$, respectively $[12,13]$. CRP levels were measured using a high-sensitivity immunoassay (Hemagen Diagnostics Inc., Columbia, Md., USA).

Serum insulin levels were measured by using a RIA kit (Sorin Saluggia, Vercelli, Italy). Insulin sensitivity was estimated by using the homeostatic model assessment (HOMA-R) index (i.e. plasma glucose level $\times($ plasma insulin level/22.5)), which was validated with the euglycemic-hyperinsulinemic clamp method [14].

An electrocardiogram was done for our patients at the start of the study and during follow-up. Echocardiographic measurements were performed according to the recommendations of the American Society of Echocardiography [15]. Left ventricular mass (LVM) was calculated according to the formula described by Devereux et al. [15] and was indexed to height ${ }^{2.7}$ (LVM index, LVMI). Left ventricular hypertrophy was defined as a LVMI of $>47 \mathrm{~g} / \mathrm{m}^{2.7}$ for women or $>50 \mathrm{~g} / \mathrm{m}^{2.7}$ for men [16].

Follow-Up of Our Patients

Our patients were monitored for $24 \pm 9$ months (range 1-36). During the follow-up period, cardiovascular events (anginal episodes or myocardial infarctions, heart failure, arrhythmia, transient ischemic attacks, strokes, peripheral vascular disease, arterial or venous thrombotic episodes) were accurately recorded. Each death was reviewed and an underlying cause was recorded.

\section{Statistical Analyses}

Data were expressed as mean \pm SD or percentage. Between groups, comparisons were made with the t test. Relationships between plasma ADPN levels and other covariates were analyzed by using Spearman rank coefficients or the least-squares method. Cox proportional hazards regression was used to evaluate the effect of plasma ADPN on cardiovascular and mortality outcomes. Variables with independent effects on survival rates were identified by constructing hierarchical models. Hazard ratios (HR) and their 95\% confidence intervals (CI) were calculated with the use of the estimated regression coefficients and their standard errors in the Cox regression analysis. Time-to-event analysis of cardiovascular outcomes was done by using the Kaplan-Meier survival curve. $\mathrm{p}$ values $<0.05$ were considered significant.

\section{Results}

\section{Plasma ADPN Levels}

The main clinical and biochemical characteristics of the studied groups are summarized in table 1. Plasma ADPN levels among HD patients $(18.1 \pm 6.8 \mu \mathrm{g} / \mathrm{ml})$ were approximately 3 times higher $(\mathrm{p}<0.0001)$ than the

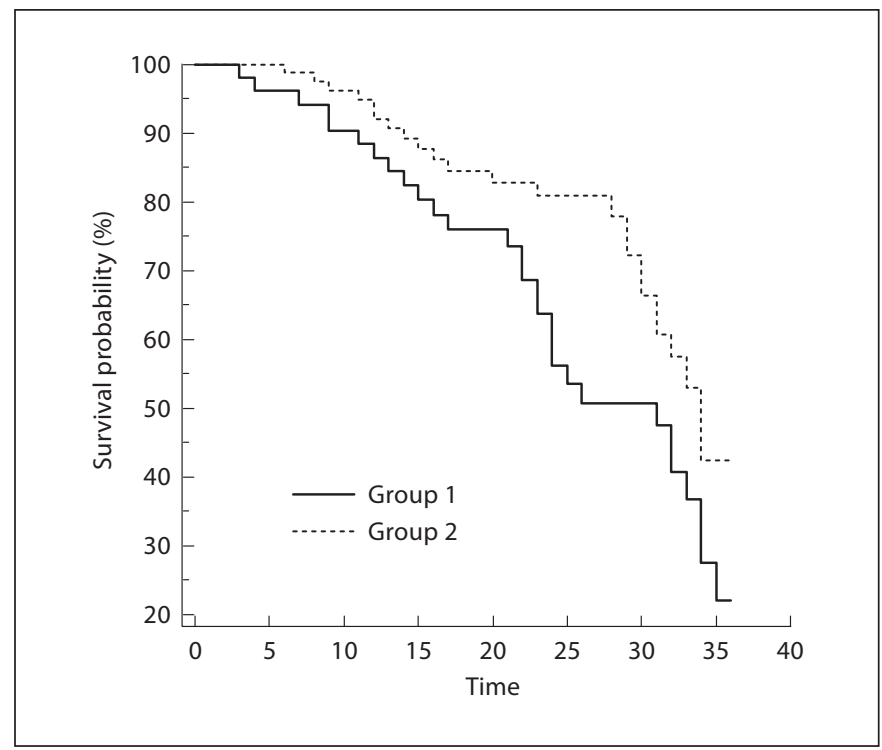

Fig. 1. Kaplan-Meier survival curves for analysis of time (months) to cardiovascular events. Patients were divided into two groups according to plasma ADPN levels (group 1, ADPN $<15.1 \mu \mathrm{g} / \mathrm{ml}$; group 2 , ADPN $\geq 15.1 \mu \mathrm{g} / \mathrm{ml}$ ). HR 0.579 , 95\% CI 0.3352-1.0012, $\mathrm{p}=0.0412$.

average value for healthy subjects $(6.2 \pm 1.8 \mu \mathrm{g} / \mathrm{ml})$ (table 1) and exceeded the upper limit of the normal range for the majority of HD patients (84 of 133 patients, i.e. $63.16 \%)$.

Among HD patients, plasma ADPN levels were higher $(\mathrm{p}<0.0059)$ for women $(18.6 \pm 8.1 \mu \mathrm{g} / \mathrm{ml})$ than for men $(15.1 \pm 6.3 \mu \mathrm{g} / \mathrm{ml})$, and this difference remained significant after data adjustment for BMI $(\mathrm{p}=0.02)$. The gender difference in plasma ADPN levels among HD patients was similar to that observed for healthy control subjects (men $5.3 \pm 1.6 \mu \mathrm{g} / \mathrm{ml}$, women $7.4 \pm 1.7 \mu \mathrm{g} / \mathrm{ml}$ ).

Plasma ADPN levels were lower $(\mathrm{p}<0.0007)$ among patients who experienced new cardiovascular events (13.9 $\pm 6.4 \mu \mathrm{g} / \mathrm{ml}$ ) than among event-free patients $(18.6 \pm 8.4$ $\mu \mathrm{g} / \mathrm{ml}$ ) (table 1). The relative risk of cardiovascular events was 1.96 times (95\% CI 1.290-2.977, $\mathrm{p}=0.0016$ ) higher among patients in group 1 (ADPN $<15.1 \mu \mathrm{g} / \mathrm{ml})$, compared with those in group 2 (ADPN $\geq 15.1 \mu \mathrm{g} / \mathrm{ml}$ ) (fig. 1).

\section{Biochemical and Clinical Correlates of Plasma ADPN Levels among HD Patients}

Plasma ADPN levels were inversely related to BMI $(\mathrm{r}=-0.295, \mathrm{p}=0.0006)$ as well as to insulin levels $(\mathrm{r}=$ $-0.2786, p=0.0012$ ) (fig. $2 a$ ) and HOMA-R indices and serum glucose levels among both men and women $(\mathrm{r}=$ $-0.406, p=0.003$ ). 

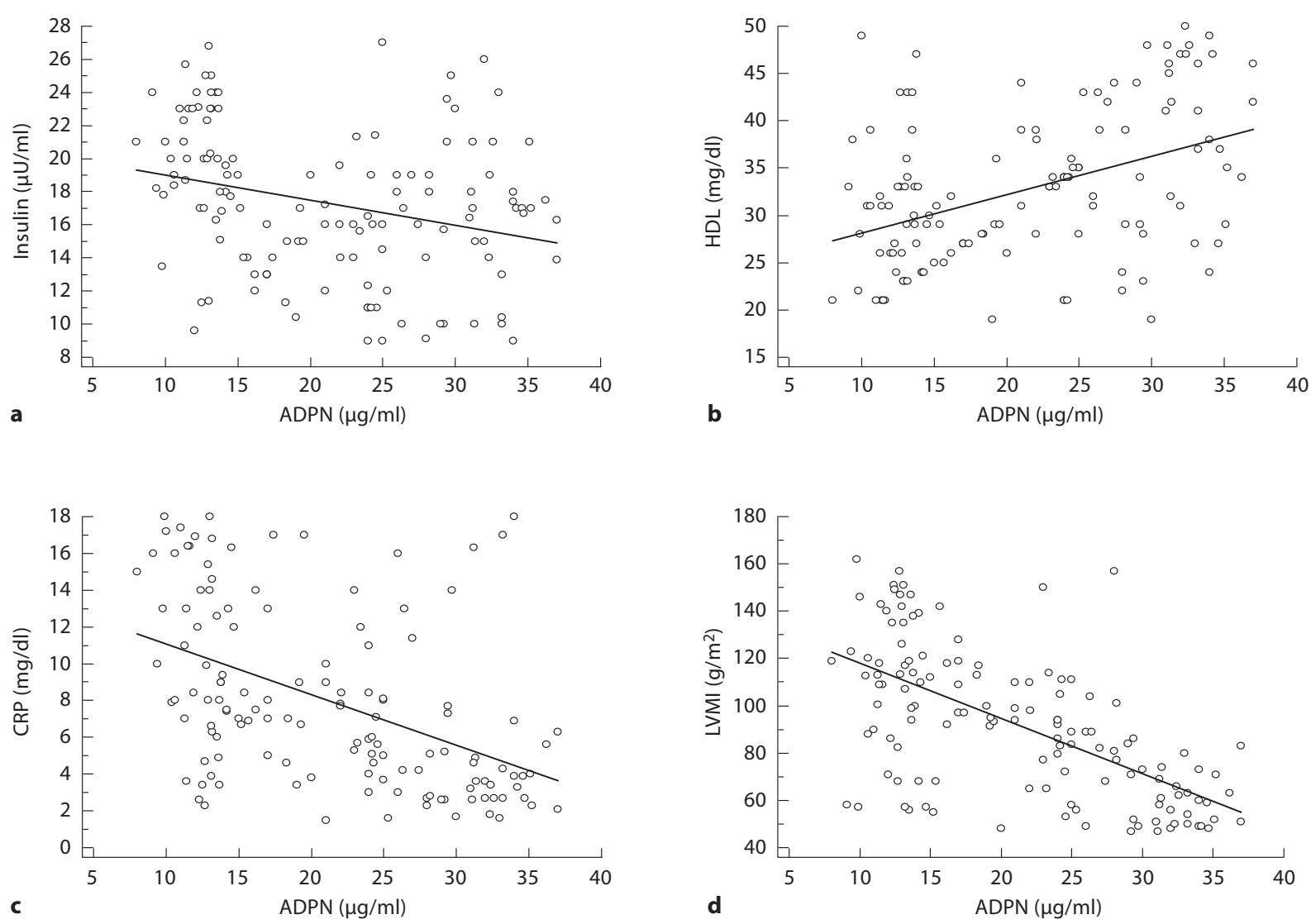

Fig. 2. a Correlation between plasma $A D P N$ and plasma insulin levels in HD patients $(r=-0.2786,95 \% \mathrm{CI}$ -0.4285 to $-0.1138, \mathrm{p}=0.0012)$. $\mathbf{b}$ Correlation between plasma ADPN and HDL-C in HD patients $(\mathrm{r}=0.4232$, 95\% CI 0.2726-0.5536, $\mathrm{p}<0.0001)$. c Correlation between plasma ADPN and CRP in HD patients $(\mathrm{r}=-0.4732$, $95 \%$ CI -0.5955 to $0.3296, \mathrm{p}<0.0001)$. $\mathbf{d}$ Correlation between plasma ADPN and LVMI in HD patients $(\mathrm{r}=$ $-0.6211,95 \%$ CI -0.7157 to $-0.5042, \mathrm{p}<0.0001)$.

Plasma ADPN levels were also inversely related to serum LDL-C $(\mathrm{r}=-0.412, \mathrm{p}=0.03)$ and TGs levels for both genders $(\mathrm{r}=-0.526, \mathrm{p}<0.0001)$. Plasma ADPN levels were directly related to plasma HDL-C $(\mathrm{r}=0.423, \mathrm{p}<$ 0.0001) (fig. 2b).

Plasma ADPN levels were inversely related to CRP $(\mathrm{r}=-0.473, \mathrm{p}<0.0001)$ (fig. $2 \mathrm{c})$, and also inversely related to LVMI ( $\mathrm{r}=-0.621, \mathrm{p}<0.0001)$ (fig. $2 \mathrm{~d}$ ).

Plasma ADPN levels were lower $(\mathrm{p}<0.04)$ among diabetic patients $(12.9 \pm 1.7 \mu \mathrm{g} / \mathrm{ml})$ than among nondiabetic patients $(17.1 \pm 1.6 \mu \mathrm{g} / \mathrm{ml})$.

Plasma ADPN levels were unrelated to age $(\mathrm{p}=0.16)$, smoking $(p=0.23)$, duration of dialysis $(p=0.18)$, mean arterial pressure $(\mathrm{p}=0.56)$, and serum albumin levels $(\mathrm{p}=0.14)$.

\section{Cardiovascular Events and Mortality during \\ Follow-Up}

Fifty-three cardiovascular events (fatal or nonfatal) occurred during the follow-up period. Using univariate and multivariate analysis, plasma ADPN seem to predict cardiovascular events in unadjusted analysis ( $\mathrm{p}=$ 0.05 ) and the strength of the association is increased after adjustment for patient-related variables $(\mathrm{p}<0.01)$ (table 2).

A total of 36 patients died, 77.8\% (28/36) of all deaths were due to cardiovascular causes. Plasma ADPN levels seem to predict overall cardiovascular mortality $(\mathrm{p}<$ 0.01 ), using univariate and multivariate analysis after adjustment for patient-related variables. Although the relationship between ADPN and all-cause mortality did not 
Table 2. Univariate and multivariate Cox regression models for the relationship between ADPN levels and outcomes

\begin{tabular}{|c|c|c|c|c|c|c|}
\hline \multirow[t]{2}{*}{ Variables } & \multicolumn{3}{|c|}{ All-cause mortality } & \multicolumn{3}{|c|}{ Cardiovascular events/mortality } \\
\hline & HR & $95 \%$ CI & $\mathrm{p}$ & HR & $95 \%$ CI & $\mathrm{p}$ \\
\hline \multicolumn{7}{|l|}{ Unadjusted analysis } \\
\hline ADPN & 1.10 & $0.74-1.19$ & 0.06 & 0.98 & $0.95-0.99$ & 0.05 \\
\hline Age & 1.02 & $1.00-1.04$ & $<0.01$ & 1.04 & $1.02-1.06$ & $<0.01$ \\
\hline Male gender & 0.86 & $0.60-1.40$ & 0.31 & 0.86 & $0.59-1.24$ & 0.36 \\
\hline Smoking & 1.46 & $1.00-2.12$ & 0.05 & 1.52 & $1.03-2.25$ & 0.03 \\
\hline Mean BLP & 0.99 & $0.96-1.70$ & 0.72 & 0.98 & $0.96-1.10$ & 0.42 \\
\hline Cholesterol & 0.99 & $0.94-1.10$ & 0.13 & 0.98 & $0.92-1.02$ & 0.24 \\
\hline HDL-C & 0.87 & $0.69-1.25$ & 0.30 & 1.00 & $0.99-1.01$ & 0.21 \\
\hline Diabetes & 1.16 & $0.80-1.68$ & 0.34 & 0.89 & $0.59-1.32$ & 0.55 \\
\hline LVH & 1.16 & $1.00-1.35$ & 0.05 & 1.75 & $1.13-2.71$ & 0.01 \\
\hline Previous CVD & 1.56 & $1.02-2.38$ & 0.04 & 1.64 & $1.60-2.62$ & 0.03 \\
\hline Duration of HD & 1.20 & $1.03-1.41$ & 0.13 & 1.05 & $0.88-1.23$ & 0.52 \\
\hline Albumin & 0.74 & $0.42-1.27$ & 0.26 & 1.03 & $0.59-1.77$ & 0.94 \\
\hline CRP & 1.16 & $1.00-1.35$ & 0.05 & 1.14 & $0.98-1.31$ & 0.06 \\
\hline \multicolumn{7}{|c|}{ Final adjusted analysis } \\
\hline ADPN & 1.17 & $1.08-1.28$ & $<0.01$ & 1.23 & $1.11-1.32$ & $<0.01$ \\
\hline Age & 1.03 & $1.01-1.06$ & $<0.01$ & 1.14 & $1.12-1.18$ & $<0.01$ \\
\hline Smoking & 1.70 & $1.13-2.61$ & 0.01 & 1.94 & $1.26-3.00$ & $<0.01$ \\
\hline LVH & 2.86 & $1.37-6.88$ & 0.02 & 2.47 & $1.02-6.76$ & 0.04 \\
\hline Previous CVD & 2.46 & $1.47-3.03$ & 0.002 & 2.38 & $1.32-4.31$ & 0.002 \\
\hline Duration of HD & 1.37 & $1.16-1.64$ & $<0.01$ & 1.28 & $1.06-1.55$ & 0.02 \\
\hline CRP & 1.20 & $1.02-1.41$ & 0.03 & 1.01 & $1.00-1.02$ & 0.01 \\
\hline
\end{tabular}

reach significance in the unadjusted Cox regression model $(\mathrm{p}=0.06)$, progressive adjustment for patient-related variables increased the strength of the association $(\mathrm{p}<$ 0.01) (table 2).

\section{Discussion}

The present study demonstrates that, independently of diabetes mellitus, plasma ADPN levels are markedly increased among HD patients and seem to be related to metabolic risk factors such as insulin levels and insulin sensitivity (HOMA-R index), TGs, LDL-C and HDL-C. Furthermore, our data demonstrate that the gender dependence of plasma ADPN levels is maintained in advanced renal failure. ADPN levels are inversely related to BMI, which is again in line with data for healthy subjects and diabetic patients [4].

In our study, ADPN levels have been shown to vary inversely with CVD and mortality and all-cause mortality suggesting a potential protective role for ADPN against the development of cardiovascular events in patients with kidney disease.

ADPN and CVD in HD Patients
This association is consistent with several studies. Zoccali et al. [8] showed that each $1 \mu \mathrm{g} / \mathrm{ml}$ increase in ADPN concentration was associated with a $3 \%$ risk reduction in new cardiovascular events in HD patients. Analogous results have been observed in nondiabetic patients with stage 3-4 CKD [9], where patients who developed new cardiovascular events had significantly lower ADPN levels (odds ratio $0.72,95 \%$ CI $0.58-0.89, \mathrm{p}=$ 0.002). In a recent study, Iwashima et al. [10] showed that ADPN levels were significantly higher in patients with more severe kidney impairment as assessed by CKD stage. After dividing the patients into a high and low group based upon gender-specific median values of ADPN, the low ADPN group had a significantly shorter event-free survival compared to the higher group $(<4.39$ $\mu \mathrm{g} / \mathrm{ml}$ in men, $<6.84 \mu \mathrm{g} / \mathrm{ml}$ in women, $\mathrm{p}<0.03$ ). Low plasma levels of ADPN were associated with inflammation and preexisting CVD; ADPN levels predicted cardiovascular and mortality outcomes, the relationship being extensively confounded by multiple patient-related factors [17].

In contrast to our study and the above findings, Menon et al. [18], in their analysis of 820 patients with a GFR 
range of between 13 and $55 \mathrm{ml} / \mathrm{min}$ from the MDRD (Modified Renal Diet) database, revealed a direct correlation between ADPN and the relative risk of cardiovascular mortality. In multivariable adjusted Cox models, a $1 \mu \mathrm{g} / \mathrm{ml}$ increase in ADPN was associated with a 3\% (HR $1.03,95 \%$ CI 1.01-1.05, $\mathrm{p}=0.02$ ) elevated risk for all-cause and 6\% (HR 1.06, 95\% CI 1.03-1.09, $\mathrm{p}=0.001)$ higher risk for cardiovascular mortality. The direct correlation between ADPN and CVD in the MDRD study may be due to a residual confounding effect of reduced renal function or processes accompanying CKD, but unadjusted for reduced GFR. For example, the mean GFR and ADPN in the MDRD was $32 \mathrm{ml} / \mathrm{min}$ and $6 \mu \mathrm{mol} / \mathrm{l}$ respectively, in comparison to $63 \mathrm{ml} / \mathrm{min}$ and $12 \mu \mathrm{mol} / \mathrm{l}$ correspondingly in the study by Becker et al. [9], highlighting the strong association between ADPN and GFR.

In contrast to initial studies, several recent and large studies on outcomes do not support a protective effect of high ADPN on CVD and overall mortality in CKD patients. Paradoxically, high ADPN predicts increased overall and cardiovascular mortality in CKD patients. This effect seems unrelated to direct effect of ADPN, but rather due to a process of protein-energy wasting [1].

In our study, the directions of the relationships between ADPN and several metabolic risk factors, such as insulin, TGs, and HDL-C, are all in agreement with the hypothesis that ADPN may have a protective role for the cardiovascular system among HD patients. Relatively higher ADPN levels were associated with better cardiovascular outcomes among HD patients. However, ADPN levels were increased, in comparison with healthy subjects, not only among patients without CVD, but also among those who developed cardiovascular complications in large proportions.

Low serum concentrations of HDL-C are associated with increased CVD risk in the general population, as well as in patients with chronic renal failure [19]. Our study demonstrated that HD patients with cardiovascular events had lower HDL levels than event-free patients, but not statistically significant.
We also demonstrated that ADPN varied inversely with CRP ( $p<0.0001)$. In multiple studies, ADPN has been shown to be inversely associated with markers of inflammation including CRP $[20,21]$. ADPN has also been shown to exhibit anti-inflammatory activity in atherosclerotic experimental models [22, 23]. In addition, ADPN ameliorates vascular VSMC proliferation by inhibition of mitogen-activated protein kinase, increases production of nitric oxide and tissue inhibitor of metalloproteinase-1, resulting in vasodilatation and decrease in plaque rupture, respectively [24].

It can be hypothesized that in ESRD the biologic phenomena underlying the cardiovascular protective role of ADPN must be downregulated, perhaps at the receptor level, thus resetting at a higher plasma concentration the relationship between this protein and cardiovascular damage and clinical complications.

Hyperinsulinemia and in cultured endothelial cells, high concentrations of cystatin $\mathrm{C}$ abolish the vasculoprotective effect of ADPN [25]. This hypothesis must be fully tested in in vitro and in vivo experiments, to better elucidate the role of this most interesting cy tokine in human diseases. Limitation to this study that we did not evaluate nutritional status in our study and protein-energy wasting is very important for cardiovascular events and mortality and we need to follow-up ADPN levels measurements in relation to cardiovascular events and mortality.

\section{Conclusion}

We found a significant inverse relationship between plasma ADPN and CVD and mortality outcomes in HD patients. The directions of the relationships between ADPN and several metabolic risk factors, such as insulin, TGs, and HDL-C, indicate that ADPN has a protective role in prevention of $\mathrm{CVD}$.
References
1 Park SH, Carrero JJ, Lindholm B, Stenvinkel P: Adiponectin in chronic kidney disease has an opposite impact on protein energy wasting and cardiovascular risk: two sides of the same coin. Clin Nephrol2009;72:599-606.

2 Pham PT, Pham PC, Donovitch GM: Cardiovascular disease posttransplant. Semin Nephrol 2007;27:430-444.
Whitehead JP, Richards AA, Hickman IJ, Macdonald GA, Prins JB: Adiponectin - a key adipokine in the metabolic syndrome. Diabetes Obes Metab 2006;8:264-280.

4 Hotta K, Funahashi T, Arita Y, et al: Plasma concentrations of a novel, adipose-specific protein, adiponectin, in type 2 diabetic patients. Arterioscler Thromb Vasc Biol 2000; 20:1595-1599. 
5 Iwashima Y, Katsuya T, Ishikawa K, et al: Association of hypoadiponectinemia with smoking habit in men. Hypertension 2005; 45:1094-1100.

6 Dzieliñska Z, Januszewicz A, Wiecek A, et al: Decreased plasma concentration of a novel anti-inflammatory protein adiponectin in hypertensive men with coronary artery disease. Thromb Res 2003;110:365-369.

$\checkmark 7$ Zoccali C, Mallamaci F, Panuccio V, et al: Adiponectin is markedly increased in patients with nephrotic syndrome and is related to metabolic risk factors. Kidney Int 2003; 84(suppl):S98-S102.

$\checkmark 8$ Zoccali C, Mallamaci F, Tripepi G, et al: Adiponectin, metabolic risk factors, and cardiovascular events among patients with endstage renal disease. J Am Soc Nephrol 2002; 13:134-141.

$\checkmark 9$ Becker B, Kronenberg F, Kielstein JT, et al: Renal insulin resistance syndrome, adiponectin and cardiovascular events in patients with kidney disease: the mild and moderate kidney disease study. J Am Soc Nephrol 2005;16:1091-1098.

10 Iwashima Y, Horio T, Kumada M, et al: Adiponectin and renal function, and implication as a risk of cardiovascular disease. Am J Cardiol 2006;98:1603-1608.

$\checkmark 11$ Bayes B, Lauzurica R, Granada ML, et al: Adiponectin and risk of new-onset diabetes mellitus after kidney transplantation. Transplantation 2004;78:26-30.
12 Zoccali C: Cardiovascular risk in uraemic patients: is it fully explained by classical risk factors? Nephrol Dial Transplant 2000;15: 454-457.

13 Arita Y, Kihara S, Ouchi N, et al: Paradoxical decrease of an adipose-specific protein, adiponectin, in obesity. Biochem Biophys Res Commun1999;257:79-83.

-14 Sahn DJ, Demaria A, Kisslo J, Weyman A: The Committee on M-Mode Standardization of the American Society of Echocardiography: Recommendations regarding quantitation in M-mode echocardiography. Results of a survey of echocardiographic measurements. Circulation 1978;58:10721083.

15 Devereux B, Alonso DR, Lutas EM, Gottlieb GJ, Campo E, Sachs I, Reichek N: Echocardiographic assessment of left ventricular hypertrophy: comparison to necropsy findings. Am J Cardiol 1986;57:450-458.

16 De Simone G, Daniels SR, Devereux RB, Meyer RA, Roman MJ, de Divitiis O, Alderman MH: Left ventricular mass and body size in normotensive children and adults: assessment of allometric relations and impact of overweight. J Am Coll Cardiol 1992;20: 1251-1260.

-17 Rao M, Li L, Tighiouart H, Jaber BL, Pereira BJB, Balakrishnan VS, the HEMO Study Group: Plasma adiponectin levels and clinical outcomes among haemodialysis patients. Nephrol Dial Transplant 2008;23:26192628.

-18 Menon V, Li L, Wang X, Greene T, et al: Adiponectin and mortality in patients with chronic kidney disease. J Am Soc Nephrol 2006;17:2599-2606.
19 Zimmermann J, Herrlinger S, Metzger T, Wanner C: Inflammation enhances cardiovascular risk and mortality in hemodialysis patients. Kidney Int 1999;55:648-658.

20 Ouchi N, Kihara S, Funahashi T, et al: Reciprocal association of C-reactive protein with adiponectin in bloodstream and adipose tissue. Circulation 2003;107:671-674.

21 Krakoff J, Funahashi T, Stehouwer CD, et al: Inflammatory markers, adiponectin, and risk of type 2 diabetes in the Pima Indian. Diabetes Care 2003;26:1745-1751.

22 Ouchi N, Kihara S, Arita Y, et al: Adiponectin, an adipocyte-derived plasma protein, inhibits endothelial NF- $\kappa \mathrm{B}$ signaling through a cAMP-dependent pathway. Circulation 2000;102:1296-1301.

23 Takemura Y, Ouchi N, Shibata R, et al: Adiponectin modulates inflammatory reactions via calreticulin receptor-dependent clearance of early apoptotic bodies. J Clin Invest 2007;117:375-386.

24 Arita Y, Kihara S, Ouchi N, et al: Adipocytederived plasma protein, adiponectin, acts as a platelet-derived growth-factor-BB-binding protein and regulates growth factor-induced common post-receptor signal in vascular smooth muscle cell. Circulation 2002;105: 2893-2898.

25 Komura N, Kihara S, Sonoda M, et al: Increment and impairment of adiponectin in renal failure. Cardiovasc Res 2010;86:471-477. 